\title{
Accountability and decentralisation in government: An incomplete contracts model
}

\author{
Paul Seabright \\ Churchill College, Cambridge. UK \\ Received 15 April 1995; accepted 15 September 1995
}

\begin{abstract}
This paper approaches the question of the appropriate level of decentralisation of power in government as a problem in the allocation of control rights under incomplete contracts. The model of the paper compares allocations of power to local, central and regional government as alternative means of motivating governments to act in the interests of citizens. Centralisation allows benefits from policy coordination but has costs in terms of diminished accountability, which can be precisely defined as the reduced probability that the welfare of a given region can determine the re-election of the government. The model is extended to allow for conflicts of interest within regions, and externalities between central and local governments in a federation. It is also applied to determining levels of fiscal transfer between localities, and to circumstances where governments may act as Leviathans appropriating resources for their own use.
\end{abstract}

JEL classification: $\mathrm{D} 72 ; \mathrm{H} 41 ; \mathrm{H} 70 ; \mathrm{L} 20$

Keywords: Decentralisation; Accountability; Incomplete contracts; Tiebout model

\section{Introduction}

How centralised should government be? The question has recently become highly topical for political reasons, notably the dissolution of highly centralised

\footnotetext{
* Corresponding author. Churchill College, Cambridge CB3 0DS, United Kingdom. Tel.: (44) 223 336227/335213: Fax: (44) 223 335475; e-mail: Paul.Seabright@econ.cam.ac.uk.
} 
political as well as economic systems in the former Eastern Bloc, and the deep political uncertainty surrounding the ratification of the Maastricht Treaty in the European Union. In Western Europe there has been considerable discussion of the notion of subsidiarity, to which the Maastricht Treaty makes appeal, and which enshrines the doctrine that decentralised allocations of power are to be preferred unless there are compelling reasons for centralisation (see Begg et al., 1993). This preference for decentralisation is often couched in terms of notions such as 'accountability', which are appealing political slogans but can be difficult to analyze in economic terms. In spite of the considerable analysis of the merits of decentralised economic systems in recent decades, there is far from being a consensus as to how many of the insights of this literature can be applied to assessing the relative merits of centralised and decentralised forms of government.

One reason for this is that the notion of decentralisation has been applied to the domain of government in at least two fundamentally different senses the relationship between which has often been far from clear. In the first sense, decentralisation may be used to mean that policies are differentiated according to the circumstances of different regions and localities. The considerable literature on the topic of 'fiscal federalism' sparked by the classic article of Tiebout (1956), has dealt largely with this sense of decentralisation. Tiebout claimed that, under certain circumstances, competition between jurisdictions supplying rival combinations of local public goods would lead to an efficient supply of such goods. The hypothesis has since come under heavy attack on the grounds that its conditions are so restrictive (comparably so to those of the Arrow-Debreu model of an exchange economy) as to provide no basis for normative analysis of the actual world (Pestieau, 1977; Bewley, 1981). Nevertheless, it has been widely interpreted as providing support for the view that allowing local jurisdictions discretion to compete in the provision of public goods will tend to increase the efficiency of allocation of those public goods for which the Tiebout conditions are not flagrantly violated.

In a second and arguably more fundamental sense, decentralisation may mean that the power to decide what a policy should be is devolved to some mechanism of local public choice in the regions and localities concerned. In principle, policy may be locally differentiated without any such decentralisation of power. ${ }^{2}$ The insight of the Tiebout model concerns the benefits of local differentiation of the supply of public goods in inducing individuals to reveal their true preferences for levels and combinations of public good provision by means of their location decisions. It is an insight that is available just as much to a centralised government

\footnotetext{
${ }^{1}$ There is a large literature on the nature of imperfect compctition between jurisdictions (see Wildasin (1991) for an introduction).

${ }^{2}$ Decentralisation of power is also not sufficient for differentiation, a point made in Hamlin (1991, p. 200 ).
} 
as to a decentralised one. ${ }^{3}$ For its effectiveness in inducing preference revelation, the Tiebout mechanism depends crucially on the mobility of citizens between jurisdictions, not upon where or indeed whether citizens may exercise their vote. Indeed, the model appeals to 'voting with one's feet' precisely because normal voting, which is conceived purely as a means of informing government, fails to be incentive-compatible in the case of public goods and hence has no useful role to play. ${ }^{4}$

Nevertheless, although the decentralisation of power and the local differentiation of policy can in principle be distinguished, many writers have argued (or assumed) that the former is particularly conducive to the latter, and further that its being so conducive constitutes one of its most important justifications. ${ }^{5}$ At its strongest, this claim takes the form of an assumption that centrally determined policies are necessarily regionally uniform, an assumption that is not only empirically false, but also leaves unexplained why central governments should not make full use of the informational and other benefits of regional differentiation. However, there is a milder and empirically more reasonable version of this thesis, namely that centralised political systems do tend to implement policies that are regionally more uniform than decentralised ones. An important question is why.

Answers can only be found in arguments that do not take for granted the disinterested pursuit of economic efficiency by governments. There is an important literature exploring the properties of different mechanisms for motivating politicians and bureaucrats to act in the interests of citizens. ${ }^{6}$ Sometimes the relative inflexibility of centralised policies is suggested to be the result of general nules

\footnotetext{
${ }^{3}$ That is, a central government may realise that, although citizens have an incentive to distort their answers if asked to report their preferences for public goods, it can induce them to reveal these preferences truthfully by implementing a differentiated pattern of local public good supply, and watching citizens seek out their favoured combinations. It even has a rule telling it how to determine its tax and spending policies at any location, given the perceived demand at that location, namely to act as if to maximise profits (Bewley, 1981) at that location. It can do all this without giving localities any autonomy whatsoever. Tiebout's model is best seen as a pioneering contribution to the theory of mechanism design, rather than as saying anything about the decentralisation of power in government. This view of the Tiebout approach has been espoused by a number of writers, including Weldon (1966, p. 231); Breton and Scott (1978, pp. 40-41); Hamlin (1991, p. 195); indecd, the latter goes so far as to argue (rightly) that "it is only in the presence of a central, efficiency-seeking government that the [efficient local differentiation of policy] is likely to be met".

${ }^{4}$ This is one of the main grounds for reproach levelled at the Tiebout model by Pestieau (1977).

${ }^{5}$ This line of argument goes back to de Tocqueville (1835, pp. 91-92, 161), but has many modern exponents. For example, Oates (1977, p.4) sees "a 'centralized solution' to the problem of resource allocation in the public sector as one that emphasises standardized levels of service across all jurisdictions".

${ }^{6}$ See Buchanan and Tullock (1962), Barro (1970), Rogoff (1990), Besley and Case (1993), Opinions differ widely on how effectively such mechanisms overcome agency costs: compare Wittman (1989) and Peltzman (1992).
} 
whose purpose is to restrain the discretion of politicians. ${ }^{7}$ Another possibility (not wholly incompatible with the first) is that inflexibility is the unintended and potentially unfortunate consequence of the difficulty of motivating governments to take all relevant differences between their citizens into account. This second possibility suggests a way to understand the role of decentralisation of power in the motivation of politicians: it may be the best way to create incentives for politicians to differentiate adequately between the needs of different groups of their citizens.

This paper formalises this idea as part of a more general examination of the incentive properties of a decentralized system of public choice. In particular, in doing so it makes important use of the idea that contracts (formal or informal) between citizens and their political representatives may be in significant respects incomplete. By this is meant not just the familiar point that some of the information that might be relevant to an efficient contract may be unobservable by one or more of the contracting parties; there is also the more subtle point that some information, though observable by the parties, may not be specifiable as part of the conditions of a contract. In the jargon, such information is said to be observable but not 'verifiable'. This may be either because the information is too complex to be specified in a legally watertight way, or because it may not be observable by third parties charged with enforcement such as the courts. For example, citizens may know whether they feel better off as a result of a certain policy, but it may be impossible for the courts to establish this. The policy may therefore be subject to electoral review but not to judicial review, which will be limited to considering more narrowly specified issues of legality of procedure.

However, agents that observe unverifiable information may react to it in ways that exert a powerful influence on contractual outcomes. The terms of a contract can influence these outcomes by determining which of a number of agents has the right to undertake actions that may depend on such unverifiable information. The literature on incomplete contracts (see Simon, 1951; Grossman and IJart, 1986; Hart and Moore, 1990; Aghion and Bolton, 1992; Dewatripont and Tirole, 1994) has typically focused on the question of which party in a collective enterprise (normally a firm) should have the right to undertake certain actions in management of that enterprise's assets. In a world in which contracts were complete it would make no difference to the outcome which party were allocated that right, since the contract could specify what the necessary actions should be as a function of the relevant circumstances. The allocation of agents to actions might matter on efficiency grounds because some agents would have a comparative advantage in undertaking certain actions; but it would not affect the actions actually taken. Once we take seriously the incompleteness of contracts it may matter very much who

\footnotetext{
${ }^{7}$ See Hamlin (1991, p. 196). Buchanan and Flowers (1975, pp. 134-136) suggest tax systems are constitutionally constrained to be general in response to voter risk aversion.
} 
has the power to take action, because we should presume that agents will take actions according to their interests. Deciding who should have the power to take certain actions is therefore a matter of foreseeing which agents will be most likely to act in the desired way. The allocation of power matters, in short, precisely when it is not possible to specify in advance precisely how that power should be exercised.

Although the literature has focused principally on the allocation of control rights in firms, ${ }^{8}$ the analytical framework is a natural one to use to address the question where power should be allocated within government. It is because citizens cannot take for granted that politicians and bureaucrats will act in their interests, and because they cannot write constitutions constraining precisely the way in which they will do so, that they need to allocate power carefully to those parties who will, in pursuing their own perceived interests, be most likely to further those of the citizens themselves.

The model of this paper looks at the relative merits of centralised and decentralised allocations of power as means of giving governments an incentive to act in the interests of their citizens. It is a highly simplified model: in particular, it assumes that the actions of governments cannot be directly observed by electors. It further assumes that the welfare of electors that results from governments' exercise of their power and from various random shocks, while observable by both governments and their electors, is not verifiable; governments cannot therefore be directly and contractually rewarded or punished according to the effect of their actions on electors. The most that a constitution can do is to grant to electors the power to decide whether a government may be re-elected to another term of office. The difference between centralised and decentralised government is then a matter of which groups of electors are collectively given the power to decide the government's re-election. Decentralisation gives control over the policy variables of a country to a number of different regional or local governments, but grants to the electors of each region or locality complete power to decide the government's re-election. Centralisation grants control over all of the country's policy variables to a single government, but ensures that regions and localities no longer have the ability to determine re-election individually but must do so in concert with others whose interests may not coincide with theirs.

Even in this very simplified model a crucial trade-off emerges. Centralisation allows government to reap benefits from the coordination of policies between jurisdictions. However, it has a potential cost, namely the diminished accountability of government to the wishes of any particular region or locality. This diminished accountability has a precise sense in the model: it is the reduced probability that a region will be able to choose to elect or reject a government at election time purely according to its own view of the government's performance.

\footnotetext{
${ }^{8}$ Tirole (1994) is an exception.
} 
This reduced accountability may diminish the incentive of the government to act in the interests of that region. And it is a direct consequence of the fact that each region's welfare is non-verifiable; there is no way to reward or punish a government according to its performance except by deciding whether or not to re-elect it. $^{9}$

The general existence of a potential trade-off between centralisation and accountability has long been familiar in political theory and political science. What this paper does is partly to formalise this trade-off in a way that defines accountability precisely, by taking a contracting approach to the problem of motivating politicians and applying the notion of contractual incompleteness to the problem of allocating power. But in addition the paper clarifies a number of further issues. First, the improved accountability that results from decentralisation matters not just because it enables policy to be differentiated according to the preferences of localities; accountability improves government's performance even when all localities have the same preferences. Secondly, centralised government can engage in local differentiation of policy, but only with respect to variables that are fully observable by all parties, not for variables that are only partially observable. Thirdly, the model shows the possibility of second-best phenomena: the accountability of government to some localities may actually be higher under full centralisation than under partial decentralisation. Finally, the paper applies the model to a number of other phenomena, including fiscal transfers between jurisdictions, governments that are revenue maximisers and externalities between central and local government in a federal structure.

Section 2 describes the model and derives the fundamental trade-off between policy coordination and accountability. It then applies the results to comparisons between central and local government, and between central and regional government (where regions are conceived as groups of localities). Section 3 considers two applications and an extension of the model. Section 4 concludes.

\section{Centralisation versus decentralisation: A simple model}

\subsection{The basic model}

The population in a certain country is divided between $N$ localities, ${ }^{10}$ indexed $i=1, \ldots, N$. The people will elect a government; this may be a government for

\footnotetext{
${ }^{9}$ This argument should be distinguished from one that appeals to yardstick competition as a benefit of decentralisation (see Besley and Case, 1995). Yardstick competition may help voters to know whether they should scek to replace their governments; the present argument, by contrast, assumes that voters' information does not in itself affect their wish to replace their government (which is instead determined by the exogenous availability of an alternative government), and instead examines the impact of decentralisation on their ability to do so.
} 
each locality, a single central government, or a series of regional governments for sub-national groups of localities. After the election the governments have to implement a policy vector $\boldsymbol{x}=\left\{x_{1}, \ldots, x_{i}, \ldots, x_{N}\right\}$. The local governments would choose separately and simultaneously the value of scalars $x_{1}, \ldots, x_{N}$, while a central government would choose the entire vector of policy instruments, and a regional government covering localities $i, j$, and $k$ would choose the vector $\left\{x_{i}\right.$, $\left.x_{j}, x_{k}\right\}$ In this sense we can think of $x_{i}$ as being the policy instrument of locality $i$, in that it is an instrument available to whichever authority governs locality $i$.

\subsubsection{The welfare of localities}

It is further assumed that there exists a well-defined and differentiable welfare function $U_{i}\left(x, y_{i}\right)$ for each locality (issues arising from heterogeneity within sub-national governments can be ignored for the time being, since they will be considered when we examine below the possibility of regional groupings of localities). The arguments of this function are the policy vector $\boldsymbol{x}$ and a random variable $y_{i}$ (of which more below). Without further loss of generality we assume that $U_{i}\left(x, y_{i}\right)$ is weakly increasing in $x_{i}$ (this amounts simply to the assumption that $x_{i}$ orders policy values in the same order as $U_{i}\left(\boldsymbol{x}, y_{i}\right)$ ).

The welfare of the population in any other locality $j$ may also depend positively or negatively on $x_{i}$, and that in locality $i$ on the values of the other policy variables $x_{j}$. To help intuition, where these externalities are positive we shall characterise the policies as 'complementary', since policies that help one locality also help others. Examples would include the provision of public education or through transport facilities. Where externalities are negative we shall call the policies 'competitive', since policies that help one locality are at the expense of others. Examples include those public goods the provision of which attracts tax-paying factors of production away from neighbouring localities. Some policies may have mixed effects, with positive externalities for some other localities and negative for others (for instance, a road built in locality 1 to link it with localities 2 and 3 may benefit the inhabitants of these localities but harm those of localities 4 and 5 by attracting new business away from their inferior transport infrastructure).

It is worth noting at this point that purely redistributive policies can be represented as special cases of competitive policies. Let a marginal reduction in $x_{i}$ represent a rise in tax revenue in locality $i$ which is distributed to localities $j$ in a

\footnotetext{
${ }^{10}$ Mobility between localities plays no explicit part in this model, since the focus is on voting (an interesting, though far from trivial extension would be a model in which citizens faced a choice between voting and moving). However, the assumption that localities can be characterised by a single welfare function can be thought of as implying that mobility has already played a part in sorting the population so that a reasonable degree of homogeneity of preferences characteristics single localities.
} 
set $J$. Then the marginal utility to locality $i$ of this change is related to the magnitude of the externalities in the following way:

$$
-\frac{\mathrm{d} U_{i}}{\mathrm{~d} x_{i}} \cdot \frac{1}{\left(\mu_{i}+\lambda_{i}\right)}=\sum_{j} \frac{\mathrm{d} U_{j}}{\mathrm{~d} x_{i}} \cdot \frac{1}{\mu_{j}}
$$

where $\mu_{j}$ represents the marginal utility of a unit of benefit income to locality $j$, and $\lambda_{i}$ represents the additional distortionary and administrative costs of raising that unit via taxation of locality $i$ (over and above the marginal utility such income would have for locality $i$ if it accrued as benefit income).

The values of $\left\{x_{1}, \ldots, x_{N}\right\}$ chosen by the governments are not directly observable by the population but remain the private information of the governments that choose them. The welfare of the population in each locality, while observable by both the population and the government, is not verifiable; consequently the constitution cannot specify rewards or penalties for the government conditional on the welfare attained. By contrast, welfare functions are verifiable, and consequently so are the first derivatives of welfare in each location with respect to the policies chosen at other locations. The constitution can therefore make the assignment of powers conditional upon the magnitude of these cross-derivatives. Note that the constitution need not make explicit reference to the magnitude of such externalities, but may assign powers according to implicit judgments by the framers of the constitution about their magnitude. Alternatively, where externalities vary from case to case in ways that are verifiable the constitution may specify an allocation of powers explicitly contingent on their magnitude. A good example of the latter in practice is the allocation of powers of merger control in the European union: since 1990 the question whether the EC or member states have jurisdiction over mergers has been settled with reference to the estimated magnitude of the spillovers between member states generated by the merger in question, as measured by the proportion of turnover of the merging enterprises that is realised outside their home state. ${ }^{11}$ In the terminology of this model, the Merger Regulation therefore represents a judgment that, while the costs and benefits of any particular merger are not verifiable, the proportion of those costs and benefits accruing across national frontiers is indeed verifiable.

\subsubsection{The objectives of governments}

The unobservability of government action matters in this model because higher values of $x_{1}$ to $x_{N}$ may be costly for the governments (they involve 'effort'). Indeed in this simple model we can interpret $\left\{x_{1}, \ldots, x_{N}\right\}$ directly as the levels of effort undertaken by the governments concerned. We can write $V_{i}\left(x_{i}\right)$ for the decreasing function representing the utility resulting to the government of locality $i$ from effort level $x_{i}$. Analogously $V(x)$ and $V_{R}(x)$ represent that of the national

" see Neven et al. (1993), especially pp. 196-201. 
government and the regional governments, where $R$ is the set of localities combined in a single region). Note that 'effort' need not be understood in any narrow sense as the sweat of the brow, but rather means any sacrifice of the politicians' personal preferences in favour of the interests of the electors; the latter are usually threatened much more by waste and empire-building than by indolence in the ordinary sense. Indeed, the so-called Leviathan hypothesis (to the effect that governments seek to maximise their total tax revenue; see Brennan and Buchanan (1980)) is a special case of the model in which the government's utility function ranks the $x_{i}$ according to the tax revenue they yicld (a special case considered in more detail in Section 3.2 below).

It is assumed that the marginal disutility of effort with respect to any one policy variable $x_{i}$ is the same (when evaluated at the same level of $x_{i}$ ) whether the government controlling it is a central, regional or local government. This is to ensure that neither form of government has an intrinsic advantage over the other arising from a differing marginal disutility of effort. However, it also rules out economies of scale in government management, which are an additional reason often cited for centralisation (see Breton and Scott (1978) for example).

Since effort levels are unobservable, governments must be induced to undertake such effort by the threat that they will not be re-elected if the populations are not satisfied with their levels of welfare. Effort cannot therefore be the sole component of the governments' welfare: re-election also has a value for them (the spoils of office, or 'ego-rents'), which we shall represent by $W$ for the local governments, $\alpha W$ for the central and $\alpha(R) W$ for the regional governments, where $R$ is the set of localities combined in a single region. In principle $\alpha(R)$ can be any positive function of $R$, though in practice the most interesting cases are where it lies strictly between unity and $n$, the number of localities in $R$ - that is, where holding office in more centralised government is more attractive to politicians than is holding office in local government, but there is diminishing marginal utility of resources controlled. ${ }^{12}$ The valuc of not being re-elected is normalised to zero. For the time being we also assume that politicians are risk neutral with respect to $W$ (or equivalently, that no monetary transfers between politicians and electors can be made); this rules out risk-sharing as a factor influencing the nature of the contract between citizens and politicians.

Finally, it is assumed for the time being that there are no externalities between governments (as distinct from externalities between localities). That is, one government's choice of policy does not directly affect the welfare of another government, other than through the welfare of the locality concerned. This

\footnotetext{
${ }^{12}$ de Tocqueville (1835) suggested gloomily that " the ambition of individuals grows with the power of the state; the strength of parties grow with the importance of the aim proposed; but love of country, which should combat these destructive passions, is no stronger in a vast republic than in a small one" (p. 159).
} 
assumption is made for the sake of clarity of exposition, and will be relaxed in Section 3.3 below.

\subsubsection{The determinants of re-election}

Making re-election contingent on the populations' welfare levels is an imperfect means of motivating politicians, since these welfare levels are also affected by unobserved locality-specific shocks $y_{i}$. Here we assume that these shocks are simply additive, so that

$$
U_{i}\left(\boldsymbol{x}, y_{i}\right)=U_{i}(\boldsymbol{x})+y_{i}
$$

where $\boldsymbol{y}=\left\{y_{1}, \ldots, y_{i}, \ldots, y_{N}\right\}$ is assumed to be distributed with a joint density $D(y)$ on support $\left[0, Y_{1}\right] \times \ldots \times\left[0, Y_{i}\right] \times \ldots \times\left[0, Y_{N}\right]$. To keep the model simple, it is assumed that if the welfare of the population of a locality, net of its specific shock, falls short of some deterministic reservation level $C$ (which can be interpreted as the welfare that could be expected from a rival political party), the population will wish to throw out the government. ${ }^{13}$ If the government is a local government it can simply be ejected. If it is a regional or national government, however, there will have to be enough other members of the regional or national population who feel the same way for the government to fall; the precise number will be determined by the voting rules in the constitution. Here we assume that a necessary and sufficient condition for a local government to be re-elected is for the welfare level of its population in the locality to be at least equal to $C$ (for brevity, when this welfare condition is met we shall say that the locality is 'satisfied', and conversely that the locality is 'dissatisfied' when it is not met). By contrast, a necessary and sufficient condition for a central government to be re-elected is for $K$ of its $N$ constituent populations to be satisfied. The re-election of a regional government where the region contains $n<N$ localities would need $k<K$ populations to be satisfied. Finally, we assume that the value of $C$ (and the other relevant parameters) are such as to generate an interior solution; no reasonable effort level can guarantee re-election for the government.

Centralization in this model, therefore, involves two features. Its advantage is that by allowing a government to control the policy instruments of more than one locality, it internalises any externalities between the localities. Its disadvantage is that any one locality loses its ability to eject the government purely according to its own preferences. It faces the risk that in some circumstances a government will be re-elected whom it would have wished to eject, or a government will be ejected whom it would have preferred to keep, because of the preferences of the other localities.

\footnotetext{
${ }^{13}$ Making $C$ stochastic, or locality-specific, or endogenous to some more complex dynamic specification of the model, might yield interesting conclusions in some applications but would risk obscuring the fundamental trade-off explored in this model.
} 


\subsubsection{Structure of the model}

The order of events is as follows:

1. A form of government (central, local or regional) is chosen.

2. The government(s) choose $x$.

3. The locality-specific shocks $y$ are realised (but not observed by the populations).

4. The populations' welfare is realised and they decide whether to re-elect their government(s).

The solution of the model will be used to compare the impact of alternative systems of government on the policies chosen in each region.

The objective function of local government is given by $V_{i}\left(x_{i}\right)+W$ if re-elected and $V_{i}\left(x_{i}\right)$ if not re-elected, where $V_{i}$ is strictly decreasing and concave. The objective function of national government is given by $V(\boldsymbol{x})+\alpha W$ if re-elected and $V(\boldsymbol{x})$ if not. The objective function of regional government is $V_{R}(\boldsymbol{x})+\alpha(R) W$ if re-elected and $V_{R}(\boldsymbol{x})$ if not. We assume that $\mathrm{d} V\left(x_{i}\right) / \mathrm{d} x_{i}=\mathrm{d} V_{i}\left(x_{i}\right) / \mathrm{d} x_{i}$; analogously, $\mathrm{d} V_{R}\left(x_{i}\right) / \mathrm{d} x_{i}=\mathrm{d} V_{i}\left(x_{i}\right) / \mathrm{d} x_{i}$ for all $i$ in $R$, and $\mathrm{d} V_{R}\left(x_{j}\right) / \mathrm{d} x_{j}=0$ for $j$ not in $R$.

It will be helpful to introduce the following notation for events. Let $s_{i}$ denote the event that $U_{i}(\boldsymbol{x})+y_{i} \geq C$, i.e. that locality $i$ is satisfied with its government. Conversely, $-s_{i}$ denotes the event that locality $i$ is not satisfied. Let $S^{K}$ denote the event that at least $K$ localities are satisfied with their government(s). Let $S_{i}^{K}$ denote the event that at least $K$ localities excluding $i$ are satisfied with their government, $S_{i j}^{K}$ the event that at least $K$ localities excluding $i$ and $j$ are satisfied, and so on. Finally, let $S^{k}(R)$ denote the event that at least $k$ localities in the set $R$ are satisfied, with $S_{i}^{k}(R)$ and $S_{i j}^{k}(R)$ defined analogously.

\subsection{Results and comparison of different forms of government}

We can now state precisely the respective optimisation problems of local, central and regional governments:

The government in each locality $i$ will choose $x_{i}$ to maximise

$$
\mathrm{E}\left[V_{i}\left(x_{i}\right)+W\right]=V_{i}\left(x_{i}\right)+W \cdot \operatorname{pr}\left[s_{i}\right] \text {. }
$$

The central government will choose $\boldsymbol{x}$ to maximise

$$
\mathrm{E}[\boldsymbol{V}(\boldsymbol{x})+\alpha W]=V(\boldsymbol{x})+\alpha W \cdot \operatorname{pr}\left[S^{K}\right] .
$$

The regional government of a region $R$ containing $n$ localities will choose $x_{i}$ for $i$ in $R$ to maximise

$$
\mathrm{E}\left[V_{R}\left(x_{i}+\alpha(R) W\right]=V_{R}\left(x_{i}\right)+\alpha(R) W \cdot \operatorname{pr}\left[S^{k}(R)\right]\right.
$$

where $k$ is the number of localities required to re-elect a government.

These problems yield the following sets of first-order conditions. 


\subsubsection{Local government}

By definition of $s_{i}$, the term $\mathrm{pr}\left[s_{i}\right]$ in (2.3) is just equal to the cumulative distribution of $y_{i}$ evaluated at $C-U_{i}(\boldsymbol{x})$. We can therefore immediately write the first-order conditions for the local government's problem as

$$
-\frac{\mathrm{d} V_{i}}{\mathrm{~d} x_{i}}=W \frac{\mathrm{d} U_{i}}{\mathrm{~d} x_{i}} \cdot D\left(y_{i}\right)
$$

where the expression $D\left(y_{i}\right)$ represents the marginal density of $y_{i}$ evaluated at $C-U i(x)$.

What this means is that the disutility of effort is equated to the value of staying in office multiplied by the marginal increase in probability of re-election. This marginal increase in re-election probability is itself made up of two terms, namely the marginal utility of increases in $x_{i}$ to locality $i$, and, for each unit increase in the locality's welfare, the increase in probability that, when shock $y_{i}$ is realised, locality $i$ 's welfare will exceed $C$. Note that $V_{i}$ and $Y_{i}$ need not be the same for each locality; consequently the values of $x_{i}$ chosen by the local governments may not be the same.

\subsubsection{Central government}

The first-order conditions for the central government's problem are a series of $N$ equations, one for each element of $\boldsymbol{x}$ :

$$
\begin{aligned}
-\frac{\mathrm{d} V}{\mathrm{~d} x_{i}}= & \alpha W \frac{\mathrm{d} U_{i}}{\mathrm{~d} x_{i}} \cdot D\left(y_{i}\right)\left(\operatorname{pr}\left[s_{i}^{K-1} \mid s_{i}\right]-\operatorname{pr}\left[s_{i}^{K} \mid-s_{i}\right]\right) \\
& +\alpha W \sum_{j} \frac{\mathrm{d} U_{j}}{\mathrm{~d} x_{i}} \cdot D\left(y_{j}\right)\left(\operatorname{pr}\left[S_{j}^{K-1} \mid s_{j}\right]-\operatorname{pr}\left[s_{j}^{K} \mid-s_{j}\right]\right)
\end{aligned}
$$

for $i=1, \ldots, N$ and $j$ not equal to $i$, and where the expression $D\left(y_{j}\right)$ represents the marginal density of $y_{j}$ and is evaluated at $C-U_{j}(x)$.

Proof. See Appendix

\subsubsection{Regional government}

By analogy with (2.7) we can immediately write down the $n$ first-order conditions as follows:

$$
\begin{aligned}
-\frac{\mathrm{d} V_{R}}{\mathrm{~d} x_{i}}= & \alpha(R) W \frac{\mathrm{d} U_{i}}{\mathrm{~d} x_{i}} \cdot D\left(y_{i}\right)\left(\operatorname{pr}\left[S_{i}^{k-1}(R) \mid s_{i}\right]-\operatorname{pr}\left[S_{i}^{k}(r) \mid-s_{i}\right]\right) \\
& +\alpha(R) W \sum_{j} \frac{\mathrm{d} U_{j}}{\mathrm{~d} x_{i}} \cdot D\left(y_{j}\right)\left(\operatorname{pr}\left[S_{j}^{k-1}(r) \mid s_{j}\right]-\operatorname{pr}\left[S_{j}^{k}(R) \mid-s_{j}\right]\right)
\end{aligned}
$$


for $i, j$ in $R$ and $j$ not equal to $i$, and where the expression $D\left(y_{j}\right)$ represents the marginal density of $y_{j}$ and is evaluated at $C-U_{j}(x)$.

Comparing Eqs. (2.6), (2.7) and (2.8) allows us to see the difference the degree of centralisation makes to the policies chosen by the government(s). Under all three systems - local, central and regional - the disutility of effort in implementing each policy instrument is set equal to the marginal increase in probability of re-election multiplied by the value of being re-elected. Where the systems differ principally is in the way the marginal increase in the probability of re-election is determined. The most straightforward comparison is between central and local government, so this will be discussed first.

\subsection{Comparing local and central government}

Under local government the marginal increase in the probability of the government's re-election is just the marginal increase in probability that the locality is satisfied (namely the density $D\left(x_{i}\right)$ evaluated at $\left.C-U_{i}\right)$. Under central government, however, there are four other effects to take into account:

(1) The probability that the locality is satisfied for any given level of $x_{i}$ depends on the value of those other $x_{j}$ that have spillover effects on locality $i$, and which may not be set at the same level under central as under local government. In principle centralisation could affect in either direction the probability that region $i$ is satisfied, and its being more likely to be satisfied could in turn either raise or lower the value of the marginal increase in re-election probability at any value of $x_{i}$, depending on whether the density of $y_{i}$ is increasing or decreasing at $C-U_{i}$.

(2) In the first-order conditions for central government, the probability that the locality is satisfied is multiplied by the probability that this locality is pivotal in determining the election of central government. This latter probability is represented by the term $\left(\operatorname{pr}\left[S_{i}^{K-1} \mid s_{i}\right]-\operatorname{pr}\left[S_{i}^{K}-s_{i}\right]\right)$, which is the difference between the probability that the central government is re-elected with region $i$ 's support and the probability that it will be re-elected even without it. Other things equal, this effect will lower the value of the right-hand side of Eq. (2.7) and result in a lower effort by the government and a lower utility for the population; this is a direct consequence of the reduced accountability consequent upon centralisation.

(3) There may be a greater incentive for effort due to greater spoils of office at national level (represented by the factor $\alpha$ ).

(4) The externality due to the impact of $x_{i}$ on the welfare of all other localities has now been internalised, as represented by the second term of the right hand side of (2.7). How much difference this makes to the government's effort will in turn depend on the difference it makes to the probability of re-election, which depends on both the magnitude of the externality (the cross-derivative $\mathrm{d} U_{j} / \mathrm{d} x_{i}$ ) and the 
probability that region $j$ itself is pivotal in determining the election of central government. Whether internalising this externality increases or reduces the government's effort will depend, of course, on whether the externality was positive or negative in the first place. Internalising a positive externality will increase, and a negative externality reduce, the effort of a central government compared to that of a local government.

Effect (2) has an unambiguously negative, and (3) an unambiguously positive (for $\alpha>1$ ) impact on effort at central as opposed to national level. Effects (1) and (4) are ambiguous in sign. If the positive effects outweigh the negative, a central government would implement a higher value of $x_{i}$ than would local governments.

What determines whether the population of locality $i$ is better off as a consequence of centralisation? This will depend not only on what happens to $x_{i}$, but on the impact of centralisation on all those $x_{j}$ that have spillover effects on locality $i$. Other things equal, by internalising these spillovers centralisation creates incentives for the government to set a value for each $x_{j}$ that corresponds more closely to the preferences of locality $i$ than under local government. However, other things may not be equal, for two reasons. First, by weakening the accountability of the government to the welfare of locality $j$, centralisation may result in lower values of $x_{j}$ even if these have beneficial spillovers on locality $i$ that are now internalised. Secondly, as there may be other localities subject to spillovers from $x_{j}$ that differ in sign from those on locality $i$ : the interests of these localities will now also be taken into account by centralisation, and the net result could be less favourable to locality $i$ than when the interests of both localities are ignored.

It is worth noting that, if each locality's welfare were verifiable as well as being observable, the constitution could specify rewards and penalties conditional upon welfare, and the adverse impact of centralisation on accountability would disappear. Indced, it is straightforward to see that, since there is no risk-cffort trade-off in the model, such a constitution could always implement the first-best under either form of government.

We can summarise Eqs. (2.6) and (2.7) in words:

\section{Under local government}

$\begin{array}{llll}\begin{array}{l}\text { Marginal disutility } \\ \text { of effort }\end{array}=\begin{array}{l}\text { Value of } \\ \text { re-election } \\ \text { to local } \\ \text { government }\end{array} & \times \begin{array}{l}\text { Marginal increase } \\ \text { in welfare of } \\ \text { locality due to } \\ \text { extra effort }\end{array} & & \begin{array}{l}\text { Increased } \\ \text { probability } \\ \text { locality is } \\ \text { satisfied } \\ \text { for unit }\end{array} \\ & & \begin{array}{l}\text { increase in } \\ \text { welfare }\end{array}\end{array}$




\section{Under central government}

Marginal disutility of effort equals:

$\begin{array}{llll}\begin{array}{l}\text { Value of } \\ \text { re-election } \\ \text { to central } \\ \text { government }\end{array} & \times \begin{array}{l}\text { Marginal increase } \\ \text { in welfare of } \\ \text { locality due to } \\ \text { extra effort }\end{array} \times \begin{array}{l}\text { Increased } \\ \text { probability } \\ \text { locality is } \\ \text { satisfied for } \\ \text { unit increase } \\ \text { in welfarc }\end{array}\end{array}$

plus

$\begin{array}{llll}\begin{array}{l}\text { Value of } \\ \text { re-election } \\ \text { to central } \\ \text { government }\end{array} & \times \text { SUM OF: } \begin{array}{l}\text { Marginal } \\ \text { increase in } \\ \text { welfare of } \\ \text { other }\end{array} & \times \begin{array}{l}\text { Increased } \\ \text { probability } \\ \text { other locality } \\ \text { localities }\end{array} & \begin{array}{l}\text { satisfied for } \\ \text { unit increase } \\ \text { in welfare }\end{array}\end{array} \times \begin{aligned} & \text { Probability } \\ & \text { that other } \\ & \text { locality's } \\ & \text { welfare } \\ & \text { determine's } \\ & \text { re-election }\end{aligned}$

What kinds of conclusion can be drawn from this analysis? We begin by considering the simplest case where policies are complementary (so spillovers are positive and therefore increases in effort are unambiguously a good thing for both localities). Nine conclusions can be drawn, some obvious, some less so.

\section{Positive spillovers}

(1) First, the analysis confirms the basic intuition that the case for centralisation is strengthened if there are significant spillovers between localities. That is to say, the likelihood that centralisation will increase government effort and consequently population welfare is increased if spillovers are large and positive.

(2) It also gives a precise sense to the notion that the cost of centralisation is a loss of local accountability. Here the loss of accountability is the fact that the welfare of a locality now has a probability less than one of being the decisive factor in whether or not the government is re-elected. The measure of accountability in the model is the term $\left(\operatorname{pr}\left[S_{i}^{K-1} \mid s_{i}\right]-\operatorname{pr}\left[S_{i}^{K} \mid-s_{i}\right]\right)$ in Eq. (2.7).

(3) The higher the value of $\alpha$, the stronger the case for centralisation. If $\alpha$ is greater than the reciprocal of $\left(\operatorname{pr}\left[S_{i}^{K-1} \mid s_{i}\right]-\operatorname{pr}\left[S_{i}^{K} \mid-s_{i}\right]\right)$, it may even happen that centralisation leads to higher government effort levels than decentralisation even 
without the internalisation of spillovers, because the greater desire of politicians for re-election outweighs their diminished accountability. However, although it might seem natural to think that the value of $\alpha$ might be of the order of $N$, because central governments command larger resources generally, it is important to distinguish between the value of initial election and the value of re-election. Former central politicians typically have a higher public profile and better alternative employment opportunities than former local politicians, and the value of re-election is measured relative to these alternative opportunities. In practice, the value of $\alpha$ is an empirical matter which may be quite difficult to determine, and may depend a great deal on the culture of the country concerned (the status of a city mayor, for example, is much higher in some countries than in others). It is wise not to make comparative static judgments that are dependent on its value without a convincing empirical case.

(4) A less obvious conclusion is that a positive correlation between locality-specific shocks may strengthen the case for centralisation. To see this, note that accountability in (2.7) is measured by the difference between the term $\operatorname{pr}\left[S_{i}^{K-1} \mid s_{i}\right]$, which is higher for any given value of $x$ if the shocks for the other localities are positively correlated with the shock to region $i$, and the term $\operatorname{pr}\left[S_{i}^{K} \mid-s_{i}\right]$, which is lower for any given value of $\boldsymbol{x}$ if the shocks are positively correlated. The higher this correlation, the higher the accountability of the central government to locality $i$ (or, to put it another way, the smaller the loss of accountability from centralisation).

(5) Note that this does not at all the same thing as saying that similarity between localities strengthens the case for centralisation. If differences between localities are incorporated in their different utility functions or the different distributions of their locality-specific shocks (variables that are known to populations and governments before any decision are taken), then both local and central governments are entirely capable of setting different values of $x_{i}$ and $x_{j}$ to reflect these differences. Centralisation makes neither easier nor more difficult the local differentiation of policy. It is the degree of correlation of shocks (which are not observed by the populations) that affects the degree of centralisation. To put it another way, what weakens accountability of centralised government to the localities is not the risk that localities will require different policies; it is the risk that localities will be differentially satisfied with whatever policies they have. This risk represents a cost of centralisation even if localities do not differ in their preferences for government policy.

(6) However, although a higher correlation between locality-specific shocks may strengthen the case for centralisation, it will not necessarily do so if there are multiple solutions to the first-order conditions. ${ }^{14}$ Very high correlations make such multiple solutions more likely. To see why, note that if shocks were perfectly

\footnotetext{
${ }^{14}$ I am particularly grateful to Jacques Crémer for this point.
} 


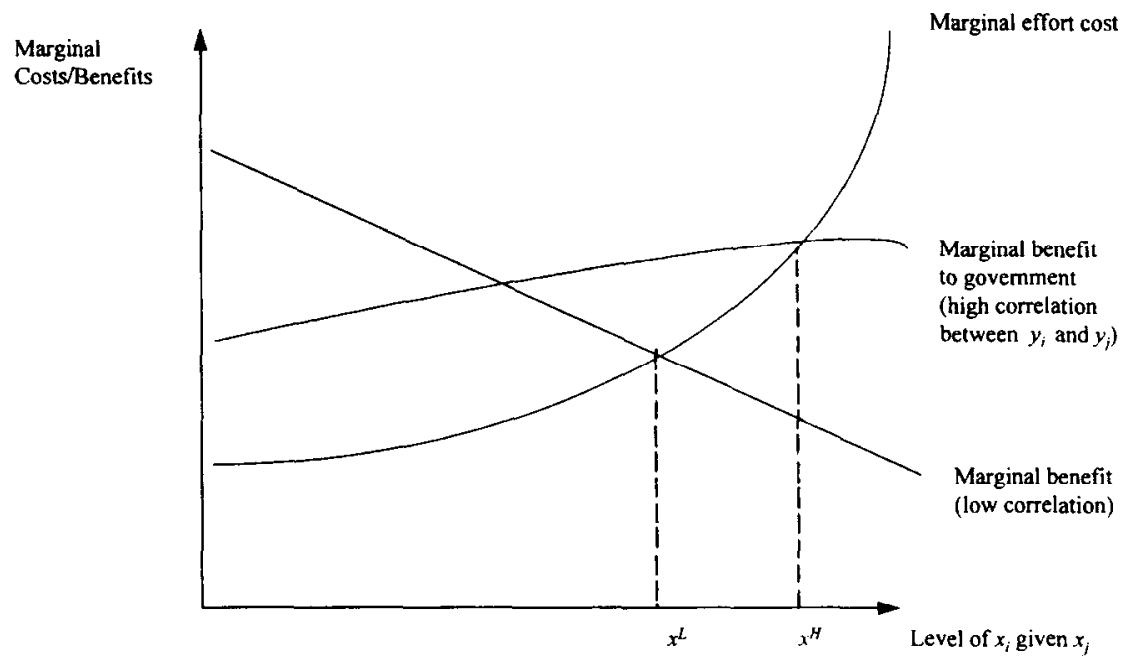

Fig. 1.

correlated across localities, a central government could concentrate all its efforts on pleasing just enough localities to be re-elected, in the knowledge that efforts to please the remaining regions would be redundant. The value of the accountability term for the remaining regions would be extremely low in spite of the high correlation between shocks, simply because it is the correlation between the different localities' satisfaction levels that counts, and this could be low because of

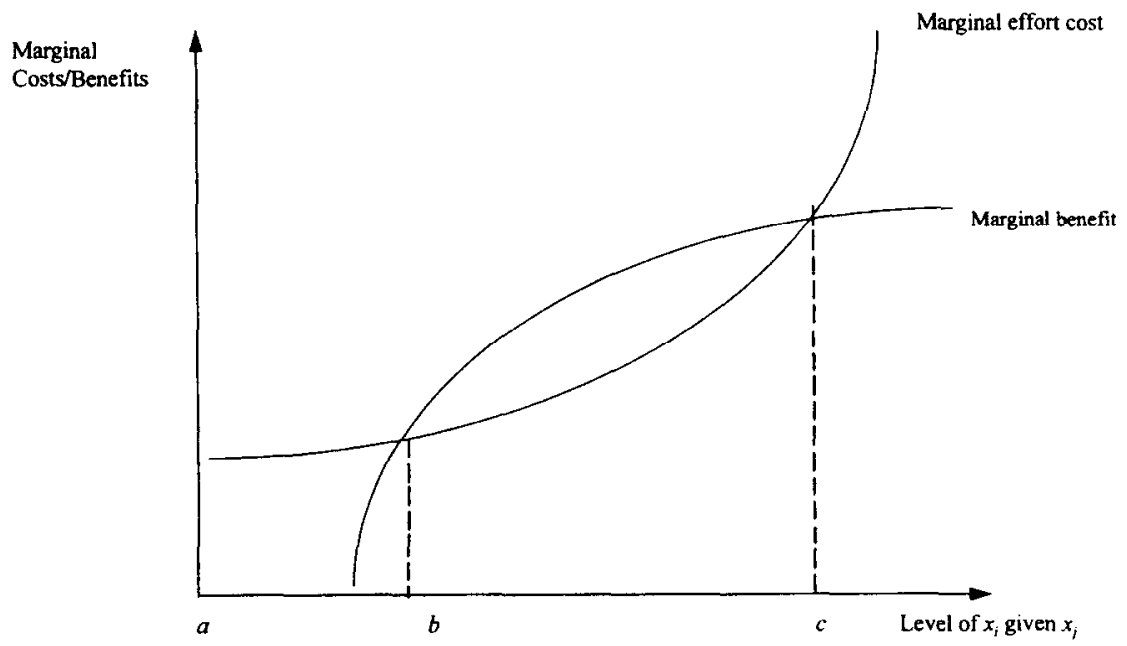

Fig. 2. 
the asymmetric distribution of government effort across localities. Figs. 1 and 2 show graphically how this might occur. In Fig. 1 a high correlation between shocks steepens the schedule representing the marginal benefit to the government from higher values of $x_{i}$ (given the values of all the $x_{j}$ ), without leading to multiple solutions, and therefore raises the equilibrium effort from $x^{L}$ to $x^{H}$. In Fig. 2 the schedule has become so steep that there are now three points $-\mathrm{a}, \mathrm{b}$ and $c$ - satisfying the first-order conditions, of which only a and $c$ are maxima, and a may yield higher benefits to the government than $c$.

(7) Even without the possibility of multiple equilibria, centralisation may benefit some localities and not others. In particular, the magnitude of spillovers may vary between localities. In such circumstances the recipients of large spillovers from other localities are more likely to benefit from centralisation than are the recipients of small ones. Localities whose probability of being the pivotal influence in the re-election of the government is sufficiently low may lose out because the government concentrates most of its efforts on other localities. ${ }^{15}$

(8) Centralisation can be achieved without great loss of accountability when governments are neither too entrenched (in the sense that localities have a low probability in equilibrium of wishing to eject them) nor too insecure (in the sense that localities have a high probability in equilibrium of wishing to eject them). This is because, if it is unlikely that one locality will want to eject its government it is relatively even more unlikely that a decisive number of localities will wish to, so the loss of accountability from centralisation is relatively great. Likewise, if it is unlikely that any one locality will wish to keep its government, it is relatively even more unlikely that a decisive number will wish to. In terms of the formal expression for accountability in Eq. (2.7), if governments are entrenched the value of the term $\operatorname{pr}\left[S_{i}^{K} \mid-s_{i}\right]$ will be relatively large, and if they are insecure the value of the term $\operatorname{pr}\left[S_{i}^{K-1} \mid s_{i}\right]$ will be relatively small, both of which will tend to diminish accountability under centralisation.

(9) The interest of citizens in one or other form of government is not necessarily shared by their political representatives. Local politicians will lose, and central politicians gain, from centralisation, whatever the benefits to their citizens. Furthermore, if some politicians are potentially mobile, in the sense that they have a significant probability of forming the government under either central or local arrangements, their incentives are perverse. They will have an interest in arguing for centralisation only when its impact in reducing accountability outweighs its beneficial impact on internalising spillovers, since under these circumstances the level of effort they have to undertake will be reduced.

(10) A choice between centralised and decentralised forms of government need not always be made once and for all, but can sometimes be undertaken on a

${ }^{15}$ I am grateful to a referee for this point. 
case-by-case basis if it is possible to estimate some of the relevant variables (such as the size of the spillovers). The European Union's Merger Regulation is a good example of such a policy in practice.

We can now ask about the effect of relaxing the assumption that spillovers are positive. Taking into account the possibility of competitive policies (those with negative spillovers) somewhat complicates the conclusions reached above.

\section{Negative spillovers}

(1) First of all, it is no longer true that higher levels of effort are unambiguously good for the welfare of populations. Taking externalities into account by centralisation may actually lower effort levels, and this may be desirable if they were previously above the efficient level (as they may have been through failing to take the externalities into account). If, however, effort was previously below the efficient level (because, for example, $W$ was too low to motivate politicians adequately), taking spillovers into account might paradoxically make both localities worse off. Locality $i$ could benefit from a reduction in the value of $x_{j}$, but lose even more by a reduction in $x_{i}$ consequent on the government's taking into account the spillover on locality $j$.

(2) Secondly, centralisation may increase the incentive for competitive policies that harm some localities. ${ }^{16}$ There are two circumstances in which this outcome is particularly to be feared. First, $\alpha$ may be very high. Suppose, for example, that high values of $x_{i}$ impose large costs on locality $j$, but that the increased spoils from centralised power make the government's enthusiasm for pleasing locality $i$ outweigh its concern for locality $j$; it may then increase the value of $x_{i}$ and make locality $j$ worse off. Secondly, there may be many localities, some of which enjoy positive and some suffer negative spillovers from the policies of locality $i$. The increased incentive due to internalising the positive spillovers on the fortunate localities may outweigh the negative spillovers on the others. Both of these adverse effects will be enhanced if the accountability of the government to the localities suffering negative externalities is particularly low. One may describe this outcome as the paradoxical result that centralisation can lead to marginalisation (of those localities whose interests are in conflict with those that are most likely to influence the actions of central government).

\subsection{Comparing central and regional government}

Much of the comparison between central and regional government raises no particularly new points of interest. Centralisation will internalise inter-regional

\footnotetext{
${ }^{16}$ Note that this is not the same thing as saying that centralisation makes available certain redistributive policies that did not exist before, though the latter is certainly an important possibility.
} 
externalities, and the calculations will be similar to those already discussed in the comparison with local government. However, two new points of importance emerge.

(1) So far it has been assumed that individual localities are sufficiently homogeneous for conflicts of interest within them to be ignored (this is what is implied by assuming the existence of a definable welfare function for each locality). The purpose of comparing central and regional government, however, is to consider possible conflicts of interest within regions. Comparison of (2.7) and (2.8) alerts us to the possibility of a second-best phenomenon: accountability for some localities may actually be higher under central than under regional government. This is because the term representing accountability in (2.8), namely $\left(\operatorname{pr}\left[S_{i}^{k-1}(R) \mid s_{i}\right]-\operatorname{pr}\left[S_{i}^{k}(R) \mid-s_{i}\right]\right)$, is not necessarily greater than the analogous term in (2.7).

Suppose, for example, that in each region there is a locality $i$ whose shock $y_{i}$ is negatively correlated with those of all other localities in that region. If this ncgative correlation is sufficiently great, the value of the expression $\left(\operatorname{pr}\left[S_{i}^{k-1}(R) \mid s_{i}\right]-\operatorname{pr}\left[S_{i}^{k}(R) \mid-s_{i}\right]\right)$ for that locality will approach zero (its chance of being pivotal becomes negligible). However, if the shocks to these marginalised localities are strongly positively correlated across regions, and the shocks to the majority localities in each region are independent across regions, then the more regions there are, the higher will be the value of the expression $\left(\operatorname{pr}\left[S_{i}^{K-}{ }^{1} \mid s_{i}\right]-\right.$ $\operatorname{pr}\left[S_{i}^{K} \mid-s_{i}\right)$ for the marginalised localities.

What is happening here is that centralisation is allowing coalitions of voters across regional boundaries. ${ }^{17}$. The power of coalitions is a function of the correlation of the shocks to the various localities that comprise them. Localities whose shocks are negatively correlated with those of other localities in their region may nevertheless comprise a formidable coalition when they can link up across regional boundaries. The same may be true of regions that link up in transnational fora (such as the European Union's new Committee of the Regions).

(2) The point made in Section 2.3 to the effect that some localities may benefit from centralisation while others lose acquires a particular urgency here, and in a dynamic model could pose serious problems of time-consistency. There may be localities that are better off under regional than central government, and others that are better off under central than regional government. Consider a locality $L$ that is better off under regional than under local government and better off under local than under central government. Suppose it is considering whether to cede powers to a regional government consisting of two other localities which are better off under central than under regional government. If regions can decide by majority

\footnotetext{
${ }^{17}$ I am grateful to a referee for this point.
} 
vote of their localities to cede their powers to the centre, locality $L$ has reason to fear the credibility of forming a regional government, since once this is formed there may be no way to prevent its powers being ceded to a central government. In this sense one may say that the mechanism of majority decision may ensure that pressures for centralisation are self-reinforcing. However, it does not follow that the result will be excessive centralisation, since locality $L$ may, through fear of this process, be unwilling to cede power to a regional government even though it would have preferred this outcome had it been credible. The result may be excessive decentralisation.

\section{Applications and an extension of the model}

\subsection{Redistribution between localities}

A special case of the model which is particular interest concerns the use of pure redistribution (by taxation), as in Eq. (2.1). Any locality is of course free to make transfers to other localities. When these are between independent localities they could be classified as foreign aid. Under centralisation, however, there is an additional motive for these transfers, which is that the central government, in disposing of its tax revenue from one locality, can use it to please another locality altogether. Assuming for simplicity that there is just one locality $j$ to which this transfer is made, we can substitute (2.1) in (2.7) and rearrange the result to yield:

$$
-\frac{\mathrm{d} V}{\mathrm{~d} x_{i}}=\alpha W \frac{\mathrm{d} U_{i}}{\mathrm{~d} x_{i}} \cdot(A-B)
$$

where

$$
\begin{aligned}
& A=D\left(y_{i}\right)\left(\operatorname{pr}\left[S_{i}^{K-1} \mid s_{i}\right]-\operatorname{pr}\left[S_{i}^{K} \mid-s_{i}\right]\right), \\
& B=\frac{\mu_{j}}{\left(\mu_{i}+\lambda_{i}\right)} \cdot D\left(y_{j}\right)\left(\operatorname{pr}\left[S_{j}^{K-1} \mid s_{j}\right]-\operatorname{pr}\left[S_{j}^{K} \mid-s_{j}\right]\right) .
\end{aligned}
$$

Comparing (2.6) with (3.1) shows that, in addition to the loss of accountability under centralisation (represented by the fact that $A$ will be less than $D\left(y_{i}\right)$ ), locality $i$ can also fear the incentive to redistribute its revenues to locality $j$. The strength of the latter is represented by term $B$. Not surprisingly, this incentive is stronger when region $j$ has a high marginal utility of income $\left(\mu_{j}\right)$, and lower when region $i$ has a high marginal utility of income $\left(\mu_{i}\right)$ or when there are high distortionary costs of raising the transfers $\left(\lambda_{i}\right)$. Eq. (3.1) therefore predicts that, other things equal, transfers should flow from richer to poorer localities, ${ }^{18}$ and

\footnotetext{
${ }^{18}$ Note, however, that (2.13) determines gross transfers from $i$ to $j$. There will also be transfers of $j$ 's tax revenue to $i$; net flows will be the difference between these two. However, the factors determining gross transfers from $i$ to $j$ will work in the opposite direction from those determining flows from $j$ to $i$, so the qualitative comparative statics are likely to be similar for gross and net flows.
} 
that this flow should be greater between localities under a central than under local government.

However, (3.1) also draws attention to the fact that the marginal utilities are not the only determinants - there is also the strength of accountability of the government to the two localities to consider. A rich locality that has a high probability of being pivotal in the voting for re-election may receive higher transfers than a poor locality that has a low probability of being pivotal. This may explain the fact that Luxembourg currently receives the highest per capita transfers from the European Union under the Structural Funds, in spite of the fact that on the World Bank's PPP-based calculations it has the highest GNP per capita of any country in the world. ${ }^{19}$

The result that flows between localities will be greater under central than local government prompts the question why localities making transfers should wish to join a grouping which is likely to require of them larger transfers than they would have wished to make anyway. In theory, localities choosing to transfer powers to a central government might seek to limit future transfers to the levels that the localities would have wished to make on their own account, but in the model - as often in reality - there is no way to make such commitments credible. Likewise, regions of a country seeking secession purely in order to limit the transfers they make to poorer regions might wish to negotiate a limit to these transfers and thereby to avoid the potentially costly and damaging effects of the secession itself (see the discussion in Dreze (1993)). However, any such limitations on transfers are likely to have weak credibility.

\subsection{The Leviathan hypothesis}

It was noted in Section 2.1 that the hypothesis that governments seek to maximise tax revenue could be seen as a special case of the model in which the government's preferences over $x_{i}$ are determined by tax revenue in locality $i$. In these circumstances spillovers between regions will be positive, since an increase in one locality's tax levels encourages marginally mobile factors to flee to other localities. These will therefore, according to Eq. (2.7), lead a central government that internalises them to raise taxation above the outcome at local level. Since the Leviathan model usually implies that tax rates even at local level are set above optimal levels, it will follow that centralisation is undesirable and that 'tax competition' between localities is to be preferred.

However, the possibility of heterogeneity within regions means that this conclusion cannot be straightforwardly applied to the comparison between regional and central government. A more realistic account would take note of the possibility that even governments that derive pleasure from large budgets may be

\footnotetext{
${ }^{19}$ World Bank (1994), cited in The Financial Times, 30 December 1994, p. 3.
} 
'captured' by interest groups with preferences for lower taxation than is representative of most of the population. There are two ways in which this process might be modelled. First, coalitions of voters across regional boundaries are more likely to consist of rich than of poor voters. Rich voters are more likely to derive taxable income from capital that is internationally diversified, so that shocks are correlated across regional boundaries; poor voters, by contrast, are more likely to depend on labour income the shocks to which are more regionally specific. Then the effect of centralisation is to increase the influence of rich voters in the overall policy-making process, and therefore potentially to lower the willingness of the government to raise taxes.

A second approach would be to suggest that governments derive benefit not only from overall taxation resources, but also from other resources whose degree of substitutability with private benefits is higher. For example, each dollar of resources given as campaign contributions to a political party may bring it greater utility than the same dollar given as taxation. Governments may therefore be willing to make implicit or explicit bargains with certain groups to lower their overall tax-and-contribution burdens in return for an increase in the fungibility of their support. If, as seems plausible, the groups who are most able to direct relatively fungible resources towards government in this way are also the groups with preferences for low levels of taxation and expenditure relative to the population as a whole, then even Leviathan governments may tax too little, and centralisation may be more to be welcomed than feared.

A final point to note is that taxation spillovers in the Leviathan context should properly be modelled as spillovers between governments and not just spillovers between localities (though doing so would not affect the qualitative results). This is because the movement of taxable factors of production between localities not only affects the welfare of those localities but directly affects tax revenue given the tax rates that governments have set. So far direct externalities between governments have been assumed to be zero, but the next section explores the consequences of relaxing this assumption.

\subsection{Externalities between governments: the separation of powers}

In the basic model it was assumed that, while there may be spillovers between localities, there are no direct externalities between governments. The model can be extended to take such externalities into account by specifying $V_{i}(x)$ instead of $V_{i}\left(x_{i}\right)$ in the objective function of local government, and by assuming that some of the derivatives with respect to other $x_{j}$ are non-zero. These derivatives would form part of the first-order conditions of central and regional but not of local government. That is, the left-hand side of (2.7) and (2.8) would include not just the term $\mathrm{d} V / \mathrm{d} x_{i}$ but an additional term $\sum_{j} \mathrm{~d} V / \mathrm{d} x_{j}$.

Such a modification to the basic model raises no new issues of importance as long as the externalities are between the governments of localities. However, some 
interesting questions arise when there are externalities between central and local governments, since these can be interpreted as spillover effects between different policies affecting the same locality, and therefore bear on important questions of the separation of powers.

These are large questions which cannot be properly treated in the space available here (however, see Flowers (1988), Brennan and Hamlin (1994) and Tirole (1994) for discussions). They are nevertheless potentially important in practice since we know that even highly centralised states leave some powers in the hands of local governments, and even highly decentralised ones still allow some functions to be performed by the central authorities. We can examine briefly how the present model would characterise such a problem. A natural way to do so would be to assume that some policy $x_{j}$ affects all localities and is determined by central government (it is no longer to be interpreted as the policy associated with locality $j$, and there is no welfare function of locality $j$ associated with it). How does this affect the relative desirability of centralising the other policies?

First of all, and trivially, the level of $x_{i}$ chosen under any form of government will in general depend on the level of $x_{j}$. In itself this raises no very interesting issues, since the fact that there is a division of powers between central and local government does not in itself imply any externality between them (any more than the fact that the marginal product of labour depends on the level of capital need imply any externality between owners of labour and owners of capital). It does indicate, however, that the desirability of centralising particular policies should not be thought of in isolation from the overall portfolio of policies available to different tiers of government; the allocation of powers is a general equilibrium problem.

Nevertheless, there are many plausible circumstances in which the level of $x_{j}$ directly affects the welfare of local government (and conversely the level of $x_{i}$ may affect the welfare of central government). To put it another way, the rent available to politicians at one tier of government may depend on the actions of the other tier of government. This externality may lead to an inefficiency when powers are separated, though given the inefficiencies that already arise from the imperfect motivation of politicians, the net impact of separation is a complex second-best problem whose solution is difficult to characterise in general terms ${ }^{20}$.

One particular case of interest is the Leviathan case, where there are negative revenue externalities between central and local government (see Flowers, 1988) and where equilibrium in the absence of externalities is likely to involve excessively high tax rates. Unlike the positive externalities between local jurisdictions

\footnotetext{
${ }^{20}$ This is particularly true in a dynamic context, where inefficiencies induced by the separation of powers may be valuable in overcoming time-consistency problems. For example, Tirole (1994) cites the value of having a finance ministry that is 'tough' as a check on the ambitions of spending ministries, given the impossibility of efficient monitoring of spending projects.
} 
(where efforts by one jurisdiction to raise tax revenue lead to increased revenue for others, and where in consequence competition between jurisdictions tends to lower overall tax levels compared to the centralised outcome), the raising of tax revenue by one tier of government lowers the revenue available to another. This means that the terms $\mathrm{d} V / \mathrm{d} x_{i}$ and $\mathrm{d} V / \mathrm{d} x_{j}$ have a different sign when $x_{j}$ is a tax rate set by central government. Consequently, whereas competition between localities tends to mitigate the Leviathan problem since the externalities between governments act to mitigate the failures of the electoral system to check the ambitions of politicians, externalities between different tiers of government are of the opposite sign and tend to exacerbate the Leviathan problem.

\section{Concluding remarks}

This paper has sought to model the extent of decentralisation in government as a problem in the allocation of control rights under incomplete contracts. One advantage of this approach is that the extent to which decentralised policies can be more sensitive to differences in the needs and preferences of different localities emerges as a result of the analysis and not as an assumption. Among other conclusions of the model are the following:

(1) Decentralisation may be valuable in improving accountability of governments to their citizens even without differences in preferences between localities, to an extent that depends in somewhat complex ways on the nature of the correlation between the shocks to the welfare of different localities. When diversity in the circumstances of different localities strengthens the case for decentralised government, this is not in itself because different localities require different policies, but because it increases the risk that localities will be differentially satisfied with whatever policies they have.

(2) Improved accountability as a result of decentralization must be set against any externalities which arise from spillovers between localities.

(3) If localities are insufficiently homogeneous, decentralisation may paradoxically diminish the accountability of government to interests that are marginalised in localities but enjoy some degree of cohesiveness at central level.

(4) The net benefits of centralised government are likely to vary between policies and between localities. It can easily happen that centralisation is good for some localities and not for others.

(5) In some policy areas the allocation of power can be decided on a case-by-case basis if it is possible to measure the approximate magnitude of spillovers. European merger policy provides a good example of such a case-by-case allocation in action. 
(6) Those in power do not necessarily have the same interests with regard to the choice between centralisation and decentralisation as do the citizens they represent; their own preferences and pronouncements may therefore be a poor guide to the benefits to be expected by their citizens.

(7) Centralised governments will tend to make higher transfers between localities than those localities would have made on their own account. Beneficiaries will tend to be poorer localities, but also those with a greater probability in being pivotal in elections for central government: these localities may not always be the same.

(8) Tax externalities between central and local governments within a federation may act to exacerbate tendencies for excessive levying of taxes, contrary to the effect of such externalities between jurisdictions at the same level of government.

It is evident that the choice between centralised and decentralised forms of government is very sensitive, not only to variable features of the particular policies in question, but to estimates of the quantitative significance of phenomena - such as 'accountability' - that are in the nature of things very hard to quantify. Nevertheless, clarification of the theoretical relationships between the different costs and benefits of centralisation may provide a useful focus for future empirical estimation.

\section{Acknowledgements}

I am grateful to Erik Berglof, Helmuth Cremer, Jacques Crémer, Jeremy Edwards, Kotaro Suzumura and two referees for detailed comments on a first version, as well as to David Begg, Mathias Dewatripont, Antonio Estache, Damien Neven, Gerard Roland, Jean Tirole and Tony Venables for valuable discussions on this topic.

\section{Appendix A. Derivation of first-order conditions for central government}

There are two important differences between the objective function of central government (Eq. (2.3)) and that of local government (Eq. (2.4)). The first is that the central government must set all $N$ components of the policy vector $\boldsymbol{x}$, so that there will be a system of $N$ first-order conditions. Here we derive the condition for arbitrary policy instrument $i$. The second difference is that the central government's objective function contains the expression $\operatorname{pr}\left[S^{K}\right]$ instead of $\operatorname{pr}\left[s_{i}\right]$. We must therefore find an explicit expression for the derivative of $\operatorname{pr}\left[S^{K}\right]$ with respect to $x_{i}$. 
We can rewrite the expression $\operatorname{pr}\left[S^{K}\right]$ in the following way:

$$
\operatorname{pr}\left[S^{K}\right]=\operatorname{pr}\left[s_{i}\right] \cdot \operatorname{pr}\left[S_{i}^{K-1} \mid s_{i}\right]+\left(1-\operatorname{pr}\left[s_{i}\right]\right) \cdot \operatorname{pr}\left[S_{i}^{K} \mid-s_{i}\right] .
$$

Differentiating (A.1) with respect to $x_{i}$ and rearranging yields

$$
\begin{aligned}
\frac{\mathrm{dpr}\left[S^{K}\right]}{\mathrm{d} x_{i}}= & \frac{\mathrm{d} \operatorname{pr}\left[s_{i}\right]}{\mathrm{d} x_{i}} \cdot\left(\operatorname{pr}\left[S_{i}^{K-1} \mid s_{i}\right]-\operatorname{pr}\left[S_{i}^{K} \mid-s_{i}\right]\right)+\operatorname{pr}\left[s_{i}\right] \\
& \cdot \frac{\mathrm{d}}{\mathrm{d} x_{i}}\left(\operatorname{pr}\left[S_{i}^{K-1} \mid s_{i}\right]\right)+\left(1-\operatorname{pr}\left[s_{i}\right]\right) \cdot \frac{d}{\mathrm{~d} x_{i}}\left(\operatorname{pr}\left[S_{i}^{K} \mid-s_{i}\right]\right) .
\end{aligned}
$$

Using an expansion analogous to (A.1) but with respect to locality $j$, one can rewrite the last two terms of (A.2) as follows:

$$
\begin{aligned}
\operatorname{pr} & {\left[s_{i}\right] \cdot \frac{\mathrm{d}}{\mathrm{d} x_{i}}\left(\left[s_{i}^{K-1} \mid s_{i}\right]\right)+\left(1-\operatorname{pr}\left[s_{i}\right]\right) \cdot \frac{\mathrm{d}}{\mathrm{d} x_{i}}\left(\operatorname{pr}\left[s_{i}^{K} \mid-s_{i}\right]\right) } \\
= & \operatorname{pr}\left[s_{i}\right] \cdot \frac{\mathrm{d}}{\mathrm{d} x_{i}}\left(\operatorname{pr}\left[s_{j} \mid s_{i}\right] \cdot \operatorname{pr}\left[s_{j}^{K-2} \mid s_{i}, s_{j}\right]+\left(1-\operatorname{pr}\left[s_{j} \mid s_{i}\right]\right)\right. \\
& \left.\operatorname{pr}\left[s_{j}^{K-1} \mid s_{i},-s_{j}\right]\right)+\left(1-\operatorname{pr}\left[s_{i}\right]\right) \cdot \frac{\mathrm{d}}{\mathrm{d} x_{i}}\left(\operatorname{pr}\left[s_{j} \mid-s_{i}\right]\right. \\
& \operatorname{pr}\left[S_{i j}^{K-1} \mid-s_{i}, s_{j}\right]+\left(1-\operatorname{pr}\left[s_{j} \mid-s_{i}\right] \cdot \operatorname{pr}\left[s_{i j}^{K} \mid-s_{i},-s_{j}\right) .\right.
\end{aligned}
$$

Differentiating explicitly within the parentheses and grouping together the terms in $\mathrm{d} \mathrm{pr}\left[s_{j}\right] / \mathrm{d} x_{i}$ yields the following expression for the last two terms of (A.2):

$$
\begin{aligned}
\operatorname{pr}\left[s_{i}\right] & \cdot \frac{\mathrm{d}}{\mathrm{d} x_{i}}\left(\operatorname{pr}\left[s_{i}^{K-1} \mid s_{i}\right]\right)+\left(1-\operatorname{pr}\left[s_{i}\right]\right) \cdot \frac{\mathrm{d}}{\mathrm{d} x_{i}}\left(\operatorname{pr}\left[s_{i}^{K} \mid-s_{i}\right]\right) \\
= & \frac{\mathrm{d} \mathrm{pr}\left[s_{j}\right]}{\mathrm{d} x_{i}} \cdot\left(\operatorname{pr}\left[S_{j}^{K-1} \mid s_{j}\right]-\operatorname{pr}\left[s_{j}^{K} \mid-s_{j}\right]\right)+\operatorname{pr}\left[-s_{i} \text { and }-s_{j}\right] \\
& \cdot \frac{\mathrm{d}}{\mathrm{d} x_{i}}\left(\operatorname{pr}\left[S_{i j}^{K} \mid-s_{i},-s_{j}\right]\right)+\operatorname{pr}\left[s_{i} \text { and }-s_{j}\right] \cdot \frac{\mathrm{d}}{\mathrm{d} x_{i}}\left(\operatorname{pr}\left[s_{i j}^{K-1} \mid s_{i},-s_{j}\right]\right) \\
& +\operatorname{pr}\left[-s_{i} \text { and } s_{j}\right] \cdot \frac{\mathrm{d}}{\mathrm{d} x_{i}}\left(\operatorname{pr}\left[s_{i j}^{K-1} \mid-s_{i}, s_{j}\right]\right)+\operatorname{pr}\left[s_{i} \text { and } s_{j}\right] \\
& \cdot \frac{\mathrm{d}}{\mathrm{d} x_{i}}\left(\operatorname{pr}\left[s_{i j}^{K-2} \mid s_{i}, s_{j}\right]\right) .
\end{aligned}
$$

Just as the last two terms of (A.2) represented that component of $\mathrm{dpr}\left[S^{K}\right] / \mathrm{d} x_{i}$ that was not captured in the direct impact of $x_{i}$ on $s_{i}$, so the last four terms of 
(A.4) represent that component that is not captured in the direct impact of $x_{i}$ on either $s_{i}$ or $s_{j}$. By induction one can continue making substitutions analogous to (A.1) for all localities until there are none unaccounted for. Eq. (A.2) can therefore be rewritten as

$$
\begin{aligned}
\frac{\mathrm{d} \operatorname{pr}\left[S^{K}\right]}{\mathrm{d} x_{i}}= & \frac{\mathrm{dpr}\left[s_{i}\right]}{\mathrm{d} x_{i}} \cdot\left(\operatorname{pr}\left[S_{i}^{K-1} \mid s_{i}\right]-\operatorname{pr}\left[S_{i}^{K} \mid-s_{i}\right]\right)+\sum_{j} \frac{\mathrm{dpr}\left[s_{j}\right]}{\mathrm{d} x_{i}} \\
& \cdot\left(\operatorname{pr}\left[S_{j}^{K-1} \mid s_{j}\right]-\operatorname{pr}\left[S_{j}^{K} \mid-s_{j}\right]\right)
\end{aligned}
$$

for $j$ not equal to $i$. Substituting (A.5) in the derivative of Eq. (2.4) yields the first-order conditions in (2.7) directly.

\section{References}

Aghion, P. and P. Bolton, 1992, An incomplete contracts approach to financial contracting, Review of Economic Studies 59, 473-494.

Barro, R., 1970, The control of politicians: An economic model, Public Choice 14, 19-42.

Begg, D. et al., 1993, Making sense of subsidiarity (Centre for Economic Policy Research, London).

Besley, T. and A. Case, 1993, Does electoral accountability affect economic policy choices? Evidence from gubernatorial term limits, Working paper no. 4575 (NBER, Cambridge, MA).

Besley, T. and A. Case, 1995, Incumbent behavior: Vote-seeking, tax-setting and yardstick competition, American Economic Review 85, 25-45.

Bewley, T.. 1981. A critique of Tiebout's theory of local public expenditures. Econometrica 49, 713-740.

Brennan, G. and J. Buchanan, 1980, The power to tax: Analytical foundations of a federal constitution, (Cambridge University Press, Cambridge).

Brennan, G. and A. Hamlin, 1994, A revisionist view of the separation of powers, Journal of Theoretical Politics 6, 345-368.

Breton, A. and A. Scott, 1978, The economic constitution of federal states (University of Toronto Press, Toronto).

Buchanan, J. and M. Flowers, 1975, The public finances: An introductory textbook (Irwin, Homewood, IL).

Buchanan, J. and G. Tullock, 1962, The calculus of consent (University of Michigan Press, Ann Arbor, MI).

de Tocqueville, A., 1835, Democracy in America, Vol. I (translated by George Lawrence; edited by J.P. Mayer) (Fontana Press, London).

Dewatripont, M. and J. Tirole, 1994, A theory of debt and equity: Diversity of securities and congruence of claims, Quarterly Joumal of Economics 109, 1027-1054.

Dreze, J., 1993, Regions of Europe: A feasible status, to be discussed, Economic Policy 17, 265-307.

Flowers, M.R., 1988, Shared tax sources in a Leviathan model of federalism, Public Finance Quarterly $16,67-77$.

Grossman, S. and O. Hart, 1986, The costs and benefits of ownership: A theory of vertical and lateral integration, Journal of Political Economy 94, 691-719.

Hamlin, A., 1991, Decentralization, competition and the efficiency of federalism, The Economic Record 67, 193-204.

Hart, O. and J. Moore, 1990, Property rights and the nature of the firm, Journal of Political Economy $98,1119-1158$. 
Neven, D., R. Nuttall and P. Seabright, 1993, Merger in daylight (Centre for Economic Policy Research, London).

Oates, W., ed., 1977, The political economy of fiscal federalism (Lexington Books, Lexington, MA). Peltuman, S., 1992, Voters as fiscal conservatives, Quarterly Journal of Economics 107, 327-361.

Pestieau, P., 1977, The optimality limits of the Tiebout model, in: Oates (1977).

Rogoff, K., 1990, Equilibrium political budget cycles, American Economic Review 80, 21-36.

Simon, H., 1951. A formal theory of the employment relationship. Econometrica 19. 293-305.

Tiebout, C.M., 1956, A pure theory of local expenditures, Journal of Political Economy 64, 416-424.

Tirole, J., 1994, On the internal organization of government, Oxford Economic Papers 46, 1-29.

Weldon, J., 1966, Public goods, and federalism, Canadian Journal of Economics and Political Science $32,231$.

Wildasin, D., 1991, Some rudimentary 'duopolity' theory, Regional Science and Urban Economics 21, 393 421.

Wittman, D., 1989. Why democracies produce efficient results, Journal of Political Economy 97 , $1395-1424$.

World Bank, 1994, World Bank atlas (World Bank, Washington, DC). 